\title{
EVALUATION OF A WRF-LCZ SYSTEM IN SIMULATING URBAN EFFECTS UNDER NON-IDEAL SYNOPTIC PATTERNS
}

\author{
G MOLNÁR, T GÁL and AZ GYÖNGYÖSI
}

\author{
Department of Climatology and Landscape Ecology, University of Szeged, Egyetem u. 2., 6720 Szeged, Hungary, \\ E-mail: molnarge@geo.u-szeged.hu
}

\begin{abstract}
Summary: The modelling of meteorological variables under non-ideal (e.g. characterized by cyclonal activity) synoptic patterns is always challenging. It is particularly true, when the simulations are performed on local or neighborhood scale. In this study, the spatio-temporal distribution of urban heat island of Szeged was predicted by the Weather Research and Forecasting (WRF) model during two period with different meteorological background. During the first, a thick and permanent fog layer was located over the Carpathian Basin. The second one was dominated by a Mediterranean low that has caused high sums of precipitation. The comparison of modelled and observed variables suggested that the computed outputs showed robust consistency with the observations during the rainfall event. On the foggy days, however, WRF had difficulties to capture the daily variability of urban heat island intensity. It was due to the large underestimations of moisture circumstances.
\end{abstract}

Keywords: urban heat island, Weather Research and Forecasting model, numerical modelling, local climate zones, modified static canopy parameters

\section{INTRODUCTION}

Urban dwellers have been experiencing an increasing amount of thermal load in expanding urbanized areas. The influence of specific surface geometry on energy budget results in major distinctions on local climate related to less-developed surroundings. One of the well-known manifestation of this phenomenon is the urban heat island (UHI), a temperature increment measured over areas with high rate of built-up. UHI has negative effects, for example, on economy (e.g. elevated energy consumption due to air conditioning in summer) (Vardoulakis et al. 2013), heath care (e.g. elevated cardiovascular morbidity and mortality) (Tan et al. 2010), and air quality (e.g. elevated tropospheric ozone production) (Fallmann et al. 2016). The projected tendencies of climate change triggers positively the modification of climatic parameters on urban scale, which draws even more attention to comprehensive monitoring of local environmental issues.

In cities with temperate climate, UHI is particularly strong in the summertime nights under anticyclonic conditions. In case of high cloud fraction or precipitation, UHI becomes less pronounced or completely missing (Morris et al. 2001). At this time, thick clouds attenuate the incoming solar radiation and decrease the net solar energy at the surface. Less solar energy can store in urban fabrics, so that less energy is emitted in the night-time, which mitigates the temperature contrast between areas with different built-up ratio. The fog belongs to a special group of low-level clouds. This phenomenon develops directly over the surface and attenuates not only the shortwave part of radiation but also reflects the outgoing longwave radiation. If the fog layer is thick enough, the top of the fog behaves like an active 
surface in terms of radiation. During fog events, the latent heat flux of surface energy budget dominates over the sensible flux and heat storage terms, and so UHI will be negligible.

The elevated number of cloud condensation nuclei from anthropogenic activities leads to higher probability of cloud (and fog) formation and precipitation in urban areas (Oke 1987, Bokwa et al. 2018). The typical annual days of fog in Szeged is around 50-55, which is the consequence of the geographic location and the relatively high frequency of high-pressure synoptic patterns in autumn and winter months. Due to the projected effects of climate change, the frequency of high precipitation events will likely be increased in the forthcoming decades (Kis et al. 2017) over the Carpathian Basin. Furthermore, Péliné Németh et al. (2016) suggested that wind speed is projected to be decreased in autumn and winter months, which also triggers the physical mechanisms lead to fog formation.

The Weather Research and Forecasting (WRF; Skamarock 2008) is a nonhydrostatical, mesoscale numerical meteorological model that has been designed for both research and weather prediction purposes. In order to represent the physical processes at city scale, three urban schemes (Single Layer Urban Canopy Model (SLUCM) of Kusaka et al., 2001, Kusaka and Kimura 2004, Building Effect Parameterization (BEP) of Martilli et al. 2002, Building Energy Model (BEM) of Salamanca et al. 2010) are available for the simulations. The urban schemes have been coupled with the Noah land surface scheme (Tewari et al. 2004) through the land cover fraction parameter that partitions the grids to urban and non-urban parts. For non-urban parts, Noah calculates, for example, the heat fluxes and then adds them to the urban scheme where the urban fluxes have already been determined. The sum of the two sub-fluxes gives the final value of the fluxes.

WRF has many options to take boundary layer processes and microphysics into account. One of the most important challenge in fog and precipitation predictions is to find the optimal combination of physical schemes (Tudor 2010). Beside the appropriate representation of physical processes, the selection of initial and boundary conditions is also crucial (Bergot et al. 2005). Several studies (e.g. Rémy and Bergot 2010, Gao et al. 2018) have successfully applied data assimilation techniques to enhance their fog forecast scores instead of using initial data from global models. It was also highlighted that the assimilation of near-surface temperature and specific humidity has the greatest influence on the simulations. Steeneveld et al. (2015) highlighted that the grid configurations also impact the quality of fog analysis and forecast. Most of the studies employed a horizontal resolution of $5 \mathrm{~km}$ and bellow for the finest domain.

Up to now, we only have experiences on the behavior of WRF in urban scale under calm weather conditions. Our earlier analyses have indicated that the coupled WRF-SLUCM with an adjusted urban parameter-set has been able predict most of the features of UHI. However, it is important to test our model under various synoptic patterns to be convinced of the strengths and shortcomings of the physical setting and static database. For this reason, in this study we intended to investigate the spatio-temporal variation of UHI during a foggy and rainy period. The simulated UHI was compared to the observations of a local urban climate monitoring system (Lelovics et al. 2014). This monitoring system consist 24 stations in Szeged representing different local climate zones (LCZs, Stewart and Oke 2012) in the city (Fig. 1). 


\section{STUDY AREA}

Szeged $\left(46.25^{\circ} \mathrm{N} ; 20.15^{\circ} \mathrm{E}\right)$ is located in the middle of Great Hungarian Plain, at $79 \mathrm{~m}$ a.s.l. The city with an administration area of $280 \mathrm{~km}^{2}$ is spread on both banks of the River Tisza (Fig. 1). Szeged has a population of 162,000 that makes it the third most populated city of Hungary. The annual mean temperature and precipitation is around $10-12^{\circ} \mathrm{C}$ and $500-600$ $\mathrm{mm}$. During the year, Szeged is influenced by both oceanic and continental climate with different rates, but in general the latter is slightly dominant due to the Köppen-Geiger's climate classification $\mathrm{Cfb}$ (warm temperate climate, no dry season, warm summer) (Kottek et al. 2006).

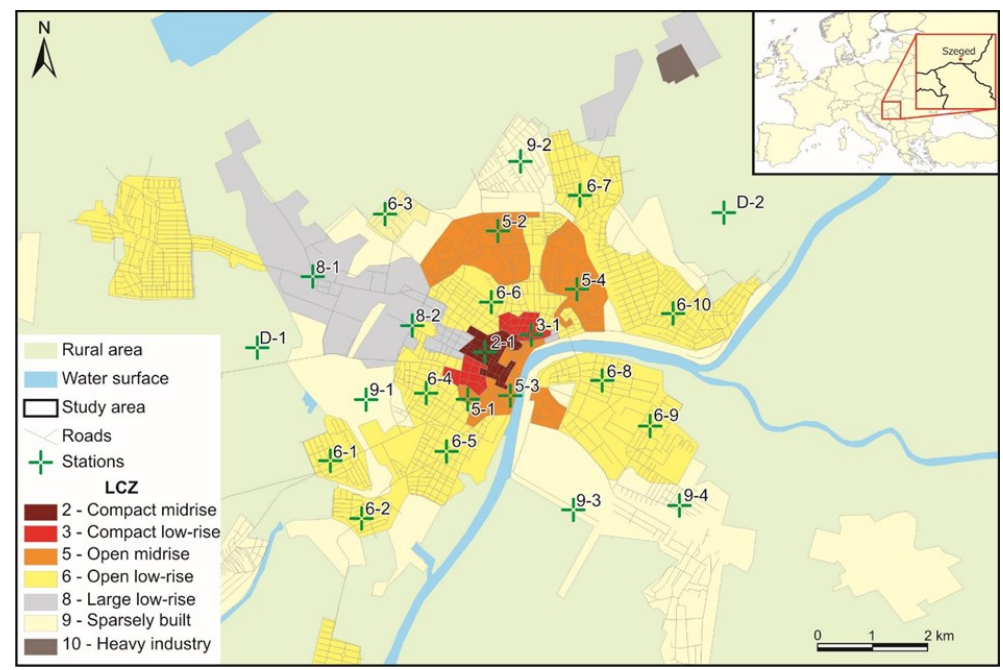

Fig. 1 Spatial distribution of local climate zones over the study area (crosses mark the sites of urban climate monitoring system)

The urbanized area consists of a well-developed and highly built-up city centre with commercials, educational and administrative buildings. In the inner residential belt, apartment houses and block of flats (mostly to the northwest) are found. On the right side of River Tisza, the residential area includes gardening houses with a larger amount green spaces. At the outermost parts with scattered cottages and logistics, the urban landscape is shifted gradually by the surrounding agricultural areas.

\section{BRIEF DESCRIPTION OF MODIFIED STATIC DATABASE}

The accurate representation of sophisticated urban geometry is essential in quantifying the physical processes within any urban area. Since each city is unique by its specific geographical, economical, and demographical features, it is required to create such static database that fits particularly well for the area of interest. To do so, several of the urban parameters (UCP) of SLUCM and BEP (Table 1) were tailored for Szeged by using threedimensional building database and remote sensing data. For taking the climate-modifying effect of surface built-up elements on local (i.e. few hundred meters to kilometer) scale into 
account, a local climate zone-based land-use categorization was incorporated to WRF. By default, the model employs only three urban land-use categories, which largely simplifies the diversity of buildings. In contrast with the default case, LCZ classification allows ten urban classes to derive a more realistic land-use data. The classes are based on the height and compactness of buildings. Additionally, the LCZ system also includes further seven nonurban categories (e.g. dense trees, bare soil, water) that describes the natural coverage of surface.

Table 1 The modified SLUCM parameters according to the LCZ system

\begin{tabular}{ccccccc}
\hline $\begin{array}{c}\text { UCP/LCZ name and } \\
\text { designation }\end{array}$ & $\begin{array}{c}\text { LCZ 2 } \\
\text { Compact } \\
\text { midrise }\end{array}$ & $\begin{array}{c}\text { LCZ 3 } \\
\text { Compact } \\
\text { low-rise }\end{array}$ & $\begin{array}{c}\text { LCZ 5 } \\
\text { Open } \\
\text { midrise }\end{array}$ & $\begin{array}{c}\text { LCZ 6 } \\
\text { Open } \\
\text { low-rise }\end{array}$ & $\begin{array}{c}\text { LCZ 8 } \\
\text { Large } \\
\text { low-rise }\end{array}$ & $\begin{array}{c}\text { LCZ 9 } \\
\text { Sparsely } \\
\text { built }\end{array}$ \\
\hline Urban fraction & 0.90 & 0.82 & 0.58 & 0.66 & 0.75 & 0.25 \\
Vegetation fraction & 0.10 & 0.18 & 0.42 & 0.34 & 0.25 & 0.75 \\
$\begin{array}{c}\text { Building height [m] } \\
\text { Road and roof width [m] }\end{array}$ & 13.6 & 7.9 & 15.4 & 5.4 & 6.6 & 5.0 \\
$\begin{array}{c}\text { Surface albedo of road, roof, } \\
\quad \text { walls }\end{array}$ & 0.15 & 0.14 & 0.12 & 0.16 & 0.16 & 0.17 \\
Thermal conductivity of road \\
$\begin{array}{c}{\left[\mathrm{Jm}^{-1} \mathrm{~s}^{-1} \mathrm{~K}^{-1}\right]} \\
\text { Thermal conductivity of roof } \\
\quad\left[\mathrm{Jm}^{-1} \mathrm{~s}^{-1} \mathrm{~K}^{-1}\right]\end{array}$
\end{tabular}

There is an option in the model in which particular thermodynamic parameters (e.g. albedo, emissivity, heat conductivity) can be assigned to the predefined land-use types. During the compilation of such data, there is a lot of impediments to be resolved. For instance, it is necessary to have detailed information of road, wall, and roof materials. Another important feature is the age and condition (e.g. leaf litter and moss coverage, wetness) of these materials that can be determined with difficulty or neglected in most cases. In this study, we made an attempt to construct the dataset of most relevant thermodynamic-related SLUCM parameters for each LCZ. In the first step, it was assumed that the dominant built-up materials are concrete and asphalt for roads and pavements, brick for walls, and ceramic (representing tiles) and concrete for roofs. Then such small areas were allocated that are representative for the given LCZ. By knowing the relative occurrence of the materials in the LCZs, the final value of a thermodynamic parameter (e.g. heat capacity) can be calculated as follows: 
$C_{L C Z_{x}}=C_{\text {asphalt }} \cdot M_{\text {asphalt }}+C_{\text {brick }} \cdot M_{\text {brick }}+C_{\text {ceramic }} \cdot M_{\text {ceramic }}+C_{\text {concrete }} \cdot M_{\text {concrete }}$

where $\mathrm{C}_{\mathrm{LCZx}}$ is the heat capacity of wall, road, or roof in a given $\mathrm{LCZ}$ in $\mathrm{J} \mathrm{m}^{-3} \mathrm{~K}^{-1}$ (x stands for building facets, i.e. wall, road, or roof), $\mathrm{C}_{\text {asphalt }}, \mathrm{C}_{\text {brick }}, \mathrm{C}_{\text {concrete }}, \mathrm{C}_{\text {ceramic }}$ is the standard heat capacity of asphalt, brick, concrete, and tile, respectively, in $\mathrm{J} \mathrm{m}^{-3} \mathrm{~K}^{-1}, \mathrm{M}_{\text {asphalt, }}, \mathrm{M}_{\text {brick }}, \mathrm{M}_{\text {concrete, }}$, $\mathrm{M}_{\text {ceramic }}$ is the relative fraction of asphalt, brick, concrete, and ceramic (tile) coverage. The standard values of the built-up materials are based on the physical look-up table of Wang and Kuo (2001). Overall, 14 SLUCM parameters (Table 1) were modified in each LCZ and applied to the simulations.

\section{MODEL CONFIGURATION}

The model integrations were performed with WRF model version 3.8.1. Three oneway nested domains were employed (Fig. 2.), with a horizontal resolution of $13.5 \mathrm{~km}$ for D01 (80×75 grids), $4.5 \mathrm{~km}$ for D02 $(121 \times 94)$, and $1.5 \mathrm{~km}$ for D03 $(106 \times 79)$.

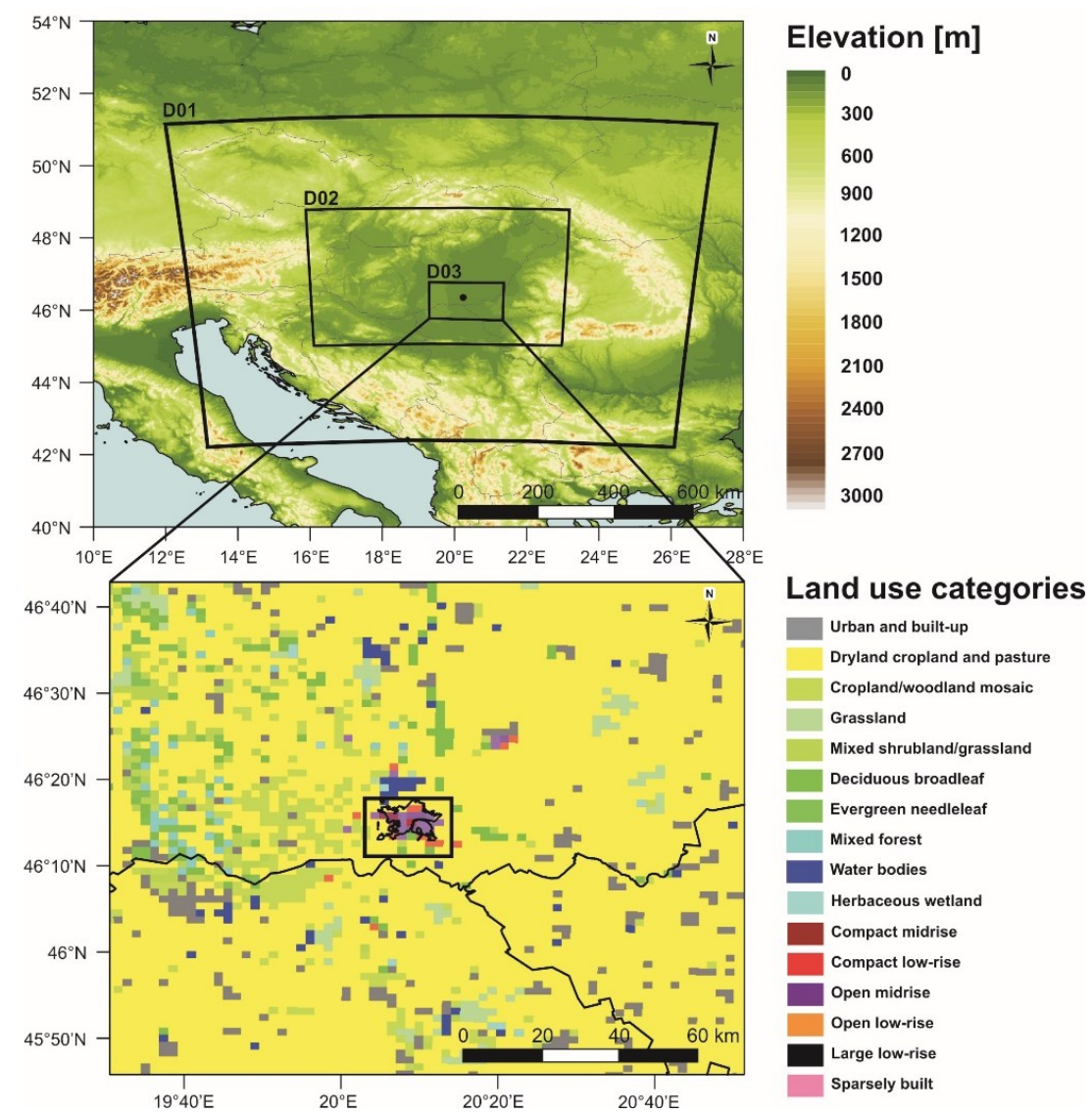

Fig. 2 Adopted domain configuration (the bottom map contains the LCZ classification for D03) 
44 sigma vertical levels were prescribed, with higher density below $2 \mathrm{~km}$ for accounting even more precisely the turbulent and microphysical processes within the urban boundary layer. Centers for Environmental Prediction (NCEP) Global Forecast System (GFS) $0.25^{\circ} \times 0.25^{\circ}$ database provided the initial and boundary conditions, with a $3-\mathrm{h}$ temporal resolution. Each simulation started at $00 \mathrm{UTC}$, one day before the period of interest, so that the first 24 hours was considered as spin-up time. In order to quantify the influence of urban geometry on local meteorological mechanisms, we have switched on the urban scheme of SLUCM. Further on, Noah land surface (sub)model (Tewari et al. 2004) was responsible for describing the surface-atmosphere interactions, RRTMG scheme (Iacono et al. 2008) for long- and shortwave radiation, revised MM5 scheme (Jiménez et al. 2012) for surface layer processes, BouLac scheme (Bougeault and Lacarrere 1989) for boundary layer processes, WSM-5 class scheme (Hong et al. 2004) for microphysics, and Kain-Fritsch scheme (Kain 2004) for cumulus convection. The Kain-Fritsch scheme was not considered for the innermost domain, since the model is able to explicitly simulate the cumulus convection at this mesh size.

The investigation concentrated on those periods when the background synoptic pattern had remarkable forcing on urban effects. During the first period, an extended anticyclone were located over Eastern Europe and Hungary, with typical mean pressures around $1035 \mathrm{hPa}$. As a result of adequate moist content in the bottom troposphere and weak synoptic winds, thick fog layer formed over the Carpathian Basin and lasted many days of which two days (21 and 22 December, 2016) has been selected for the analysis. Our second case is quite different from the previous one: a strong Mediterranean low has swept across Hungary from southwest, causing remarkable precipitation sums and high wind speeds. The peak of the cyclone activity fell between 22 and 23 October, 2017, so the influence of precipitation on UHI was examined on these days.

Table 2 Geographical information about the stations that are used for the evaluation

\begin{tabular}{cccccc}
\hline $\mathbf{N}^{\mathbf{0}}$ & LCZ & Station ID & Latitude & Longitude & Elevation [m a.s.l.] \\
\hline 1. & LCZ 2 & $2-1$ & $46.2549^{\circ} \mathrm{N}$ & $20.1611^{\circ} \mathrm{E}$ & 82 \\
2. & LCZ 5 & $5-1$ & $46.2643^{\circ} \mathrm{N}$ & $20.1402^{\circ} \mathrm{E}$ & 80 \\
3. & LCZ 5 & $5-2$ & $46.2749^{\circ} \mathrm{N}$ & $20.1646^{\circ} \mathrm{E}$ & 79 \\
4. & LCZ 5 & $5-4$ & $46.2818^{\circ} \mathrm{N}$ & $20.1832^{\circ} \mathrm{E}$ & 80 \\
5. & LCZ 6 & $6-4$ & $46.2650^{\circ} \mathrm{N}$ & $20.1470^{\circ} \mathrm{E}$ & 80 \\
6. & LCZ 6 & $6-5$ & $46.2386^{\circ} \mathrm{N}$ & $20.1350^{\circ} \mathrm{E}$ & 81 \\
7. & LCZ 6 & $6-8$ & $46.2666^{\circ} \mathrm{N}$ & $20.1722^{\circ} \mathrm{E}$ & 78 \\
8. & LCZ 6 & $6-9$ & $46.2590^{\circ} \mathrm{N}$ & $20.1834^{\circ} \mathrm{E}$ & 78 \\
9. & LCZ 6 & $6-10$ & $46.2775^{\circ} \mathrm{N}$ & $20.1892^{\circ} \mathrm{E}$ & 79 \\
10. & LCZ 9 & $9-2$ & $46.2863^{\circ} \mathrm{N}$ & $20.1535^{\circ} \mathrm{E}$ & 79 \\
11. & LCZ 9 & $9-4$ & $46.2458^{\circ} \mathrm{N}$ & $20.1901^{\circ} \mathrm{E}$ & 79 \\
12. & LCZ D & D-1 & $46.2562^{\circ} \mathrm{N}$ & $20.0903^{\circ} \mathrm{E}$ & 80 \\
\hline
\end{tabular}

The simulated near-surface air temperature $\left(\mathrm{T}_{\mathrm{nWRF}}\right)$ and relative humidity (for the fog case) was verified against the observations of urban climate monitoring system. From the modelled variables, we considered only those that are closest to the given monitoring site and characterized by same land-use category (i.e. they are in same LCZ). For example, station D1 was chosen to represent the rural measurements. The corresponding rural pair in the simulations is the value in the nearest grid to station D-1. By following this assumption, the mean UHI intensity in a given LCZ can be calculated as 


$$
\Delta T_{L C Z_{x}}=\sum_{i=1}^{m} \frac{1}{m}\left(T_{n_{i}}-T_{n_{L C Z D}}\right)
$$

where $\Delta \mathrm{T}_{\mathrm{LCZx}}$ is the modelled or observed UHI intensity in a given LCZ, $\mathrm{T}_{\mathrm{n}}$ is the modelled or observed near-surface temperature in a given LCZ, $\mathrm{T}_{\mathrm{n} \_\mathrm{LCZ}} \mathrm{D}$ is the modelled or observed rural near-surface temperature, $\mathrm{m}$ is the number of stations in a given LCZ. Precipitation measurements occur solely at station D-1, therefore the verification of precipitation sums was performed only for the rural site. Towards an efficient and comprehensive comparison, the sampling frequency of outputs was set to 10 minutes. Some of the stations indicated missing values during one of the periods, thus they were omitted from the analysis. The fundamental metadata of the remaining stations are summarized in Table 2.

\section{RESULTS AND DISCUSSION}

\section{1. "Fog case"}

\subsubsection{Evaluation of near-surface temperature}

As it can be seen in Fig. 3, the observed near-surface air temperature $\left(\mathrm{T}_{\mathrm{nOBS}}\right)$ remains below the freezing point in all LCZs during the entire simulation period. An additional common feature was the almost uniform ranges of $\mathrm{T}_{\text {nOBs }}$ between $-0.5^{\circ} \mathrm{C}$ and $-2.5^{\circ} \mathrm{C}$, with the highest peaks after 12 UTC on 22 December. In rural LCZ D, however, the mean $T_{\text {nOBS }}$ was $1-1.5^{\circ} \mathrm{C}$ lower than in urban ones. Higher temperatures within the city could be the consequence of such anthropogenic activities as transportation or heating of buildings. Due to the thick fog layer and lack of insolation, the diverse urban geometry has low impact on local meteorology, therefore only a slight inter-LCZ variability exists. If we consider $\mathrm{T}_{\mathrm{nOBS}}$ on the two days, it is clearly seen that the daytime warming stage was utterly disappeared. Usually, the fog intensifies with inconstant speed and depends on the availability of moist supply. The measured time-series of $T_{n}$ suggest that the increase of fog thickness could be permanent and conserves $T_{n O B s}$ at a given level. In order to confirm this, the evolution of moist-related variables (e.g. relative humidity) should also be taken into consideration.

The modelled near-surface temperature $\left(\mathrm{T}_{\mathrm{nWRF}}\right)$ that varies between $-4^{\circ} \mathrm{C}$ and $4^{\circ} \mathrm{C}$ shows quite different patterns from the observations in each LCZ. On average, $\mathrm{T}_{\mathrm{nWRF}}$ overestimates $T_{n O B S}$, especially during the day (Fig. 3). The daytime positive biases peaks around 12 UTC, with a magnitude of $5-6^{\circ} \mathrm{C}$ and minor distinctions between the first and second day. $\mathrm{T}_{\mathrm{nWRF}}$ at night can be typified with 2 stages. The first stage covers the first 5-6 hours when the warm biases decrease in each LCZ, and what is more in LCZ 5 and LCZ 9 the overestimation shifts to a slight underestimations of about $0.5^{\circ} \mathrm{C}$. By comparing the static SLUCM parameters and $\mathrm{T}_{\mathrm{nWRF}}$ in different LCZs, it is revealed that the cooling rate is proportional to the built-up rates of LCZs. In LCZ 2 with a mean urban fraction of $90 \%$, the maximum of $\mathrm{T}_{\mathrm{nWRF}}$ is about $3{ }^{\circ} \mathrm{C}$ higher than in LCZ 9 with a mean urban fraction of $25 \%$. During the second stage, covers the remaining night-time hours of the simulation period, the overestimations are even more obvious, although the aforementioned cooling potential is less significant. Then, the discrepancies in urban fractions are not a major factor in governing the nocturnal $T_{n W R F}$ as earlier. Consequently, the daily temperature ranges on the second day are much (around $4^{\circ} \mathrm{C}$ ) lower. A potential explanation for this may be that the emission of 
longwave radiation is lower as a result of higher air moisture content and higher low-level cloud coverage. This also emphasizes that the overview of wetness conditions is crucial in this case.
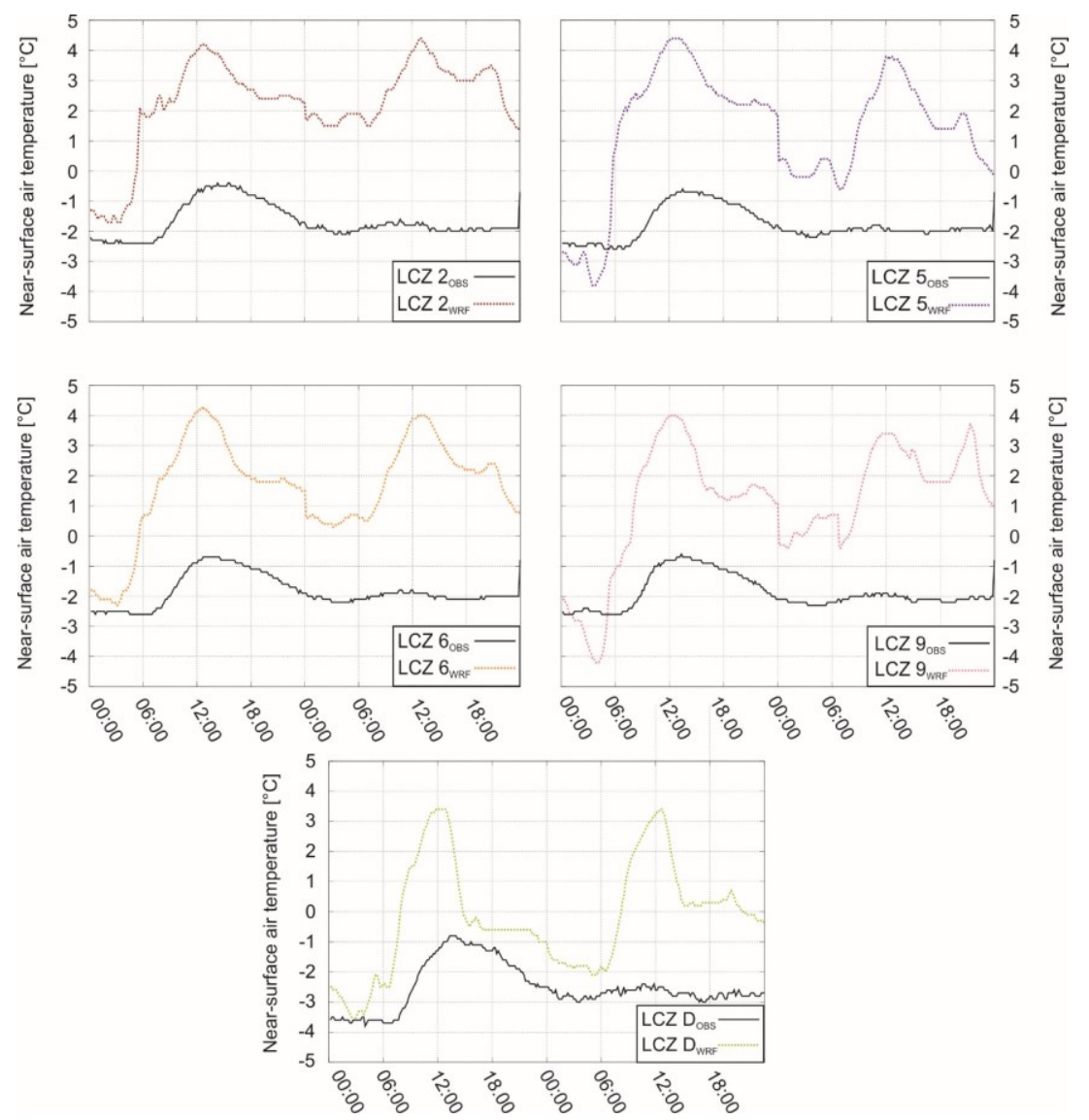

Fig. 3 Temporal variation of observed and modelled near-surface air temperature in each LCZ

\subsubsection{Evaluation of $U H I$}

The observed urban heat island intensity $\left(\Delta \mathrm{T}_{\mathrm{OBS}}\right)$ ranges within a narrow threshold between $0^{\circ} \mathrm{C}$ and $1{ }^{\circ} \mathrm{C}$ (Fig. 4), which means tiny fluctuations either in space and time. A small decrease of $0.5^{\circ} \mathrm{C}$, however, occurs on the second day because of the decreasing of $\mathrm{T}_{\mathrm{nOBS}}$ around noon. Contrarily, the modelled intensity $\left(\Delta \mathrm{T}_{\mathrm{WRF}}\right)$ shows much higher spatiotemporal variability, with a range between $-1{ }^{\circ} \mathrm{C}$ and $4^{\circ} \mathrm{C}$. Overall, $\Delta \mathrm{T}_{\mathrm{OBS}}$ is over-predicted, particularly in the night-time, with even $3-4^{\circ} \mathrm{C}$. The largest uncertainties arise in LCZs 2 and 5 at $06 \mathrm{UTC}$, when the increasing of $\mathrm{T}_{\mathrm{n}}$ is simulated to be faster in urban grids related to the rural counterpart. The positive biases in LCZs 5 and 9, however, decrease at this time due to the underestimation of $T_{n W R F}$.

In the daytime, particularly from 10 to $14 \mathrm{UTC}, \Delta \mathrm{T}_{\mathrm{WRF}}$ shows relatively good agreement with observations (Fig. 4). On the second day, however, slight underestimations 
of daytime $\Delta \mathrm{T}_{\mathrm{OBS}}$ evolves in each LCZ. Beside the similarities, there are several differences that must be pointed out. In LCZs 2 and 6, for example, the strong UHI that predicted from 15 to 08 UTC stays at a constant level of $2.5-3.5^{\circ} \mathrm{C}$. On the other hand, UHI in LCZ 5 has higher variability with a weak decrease after 01 UTC. When UHI is modelled to be positive, the mean magnitude is the lowest in LCZ 9, which is the result of low impervious and high pervious surface coverage.
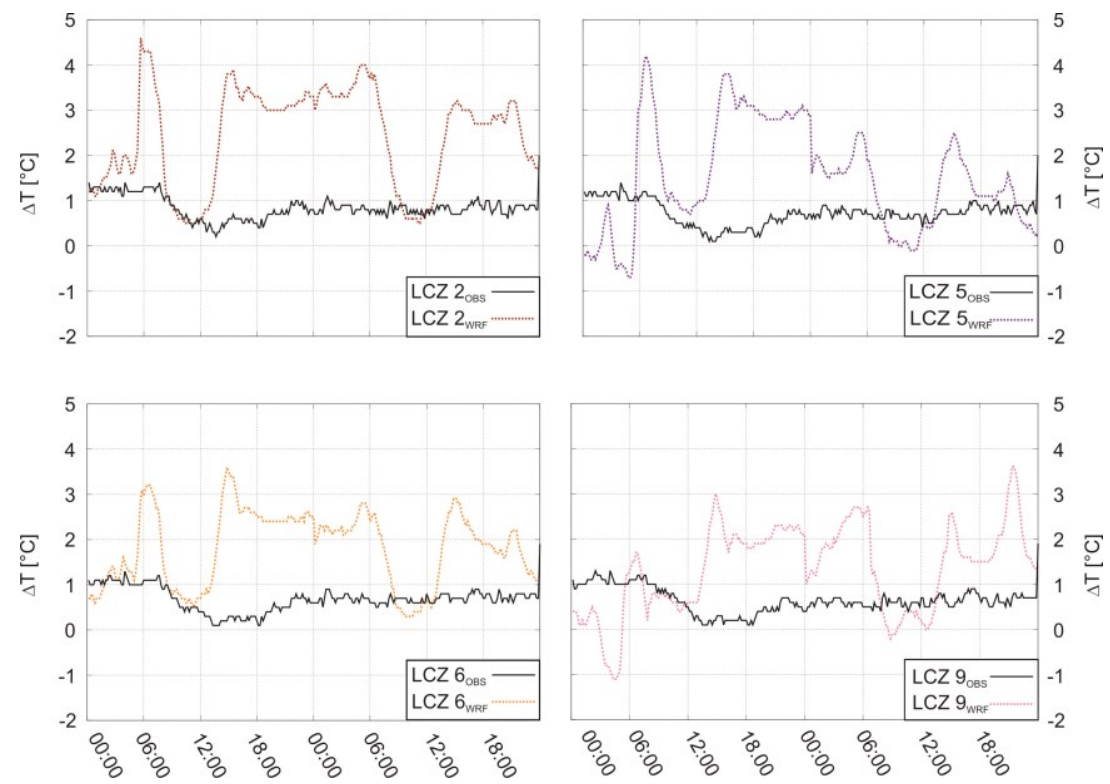

Fig. 4 Temporal variation of observed and modelled urban heat island intensity $(\Delta \mathrm{T})$ in each LCZ

Fig. 5 illustrates the spatial distribution of $\Delta \mathrm{T}_{\mathrm{WRF}}$ over the study area. As it is expected, $\Delta \mathrm{T}_{\mathrm{WRF}}$ at $12 \mathrm{UTC}$ is around $0-1^{\circ} \mathrm{C}$ on both days, with minimal areal differences. Robust heat island, with more pronounced spatial variability, is simulated at 04 UTC (representing UHI before sunrise). On the first day of the period, the negative $\Delta \mathrm{T}_{\mathrm{WRF}}$ is limited to the northern and south-western periphery of Szeged, with values around $2.5^{\circ} \mathrm{C}$. On the following day, at the same date, $\Delta \mathrm{T}_{\mathrm{WRF}}$ expands to the entire city. The hottest spots are located over the downtown (LCZs 2 and 5) and the northern parts with LCZ 6. The spatial distribution at 20 UTC (representing UHI after sunset) occurs analogously, with intensities over $2.5^{\circ} \mathrm{C}$. When the two dates are compared, it can be seen that $\Delta \mathrm{T}_{\mathrm{WRF}}$ seems to be larger on 21 December. LCZs in the middle and the north-western parts that can be considered as a transition zone from urban to rural landscape are characterized by $\Delta \mathrm{T}_{\mathrm{WRF}}$ of $2^{\circ} \mathrm{C}$ and below. In parallel, the values are mostly under $0^{\circ} \mathrm{C}$ in the adjacent rural areas, showing a cooling to the previous day. Indeed, the nocturnal $\mathrm{T}_{\mathrm{nWRF}}$ in LCZ D increases less compared to the urban LCZs, therefore the near-surface air layers in other rural grids can also cool below the mean of urban values. This contrast in cooling potential can lead to the relative difference in $\Delta \mathrm{T}_{\mathrm{WRF}}$ between the days at 20 UTC. 


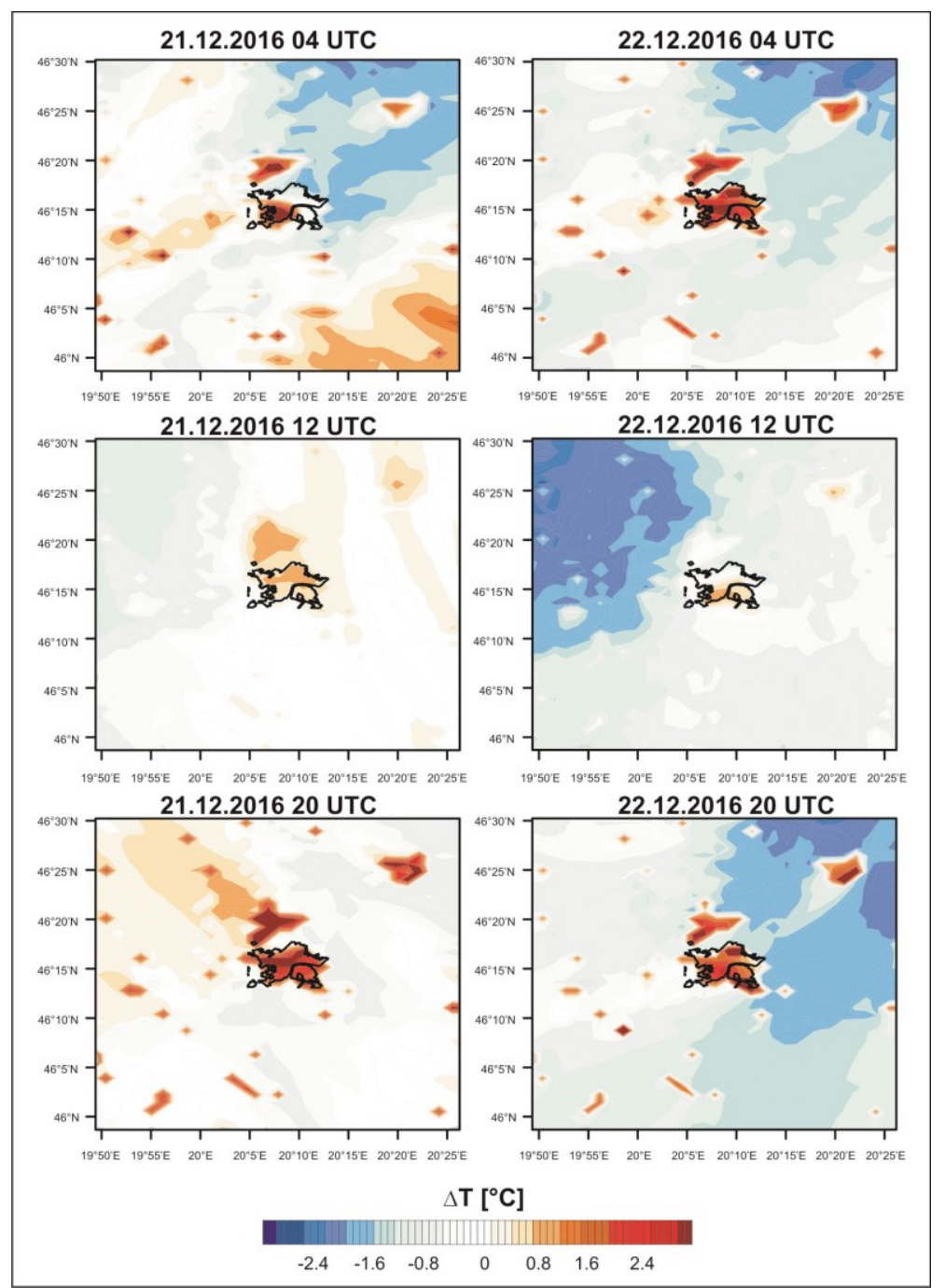

Fig. 5 Spatial distribution of modelled urban heat island intensity $(\Delta \mathrm{T})$ over the Szeged and the surroundings on six distinct dates

\subsubsection{Evaluation of relative humidity and the analysis of net shortwave radiation flux}

The presence of fog and mist in WRF simulations is further analysed on the temporal variability of relative humidity and net surface shortwave radiation flux (Fig. 6). Modelled shortwave flux has substantial daily variation with peaks around $300 \mathrm{Wm}^{-2}$ at local noon (11 UTC). This flux is similar to the climatic mean value of December, referring to low amount of cloudiness. In LCZ D, the flux is about $25 \mathrm{Wm}^{-2}$ lower than in the grid of station 5-1. It is may be the consequence of less transparent air column for solar radiation, due to higher absolute moisture content. 
One of the major criterion for fog is that the relative humidity must be over $80 \%$. By following this definition, the observations imply fog formation around the rural measurement site during the whole simulation period. The same is valid for station 5-1, however, the fog layer is likely to be broken up in the middle of the first day. The time-series of modelled relative humidity in each LCZ does not show reasonable agreement with the observations. The uncertainties as high value as $30-35 \%$ in the daytime. During the other stages of the era, the predicted relative humidity also remains under the observed standards. In the rural LCZ, the relative humidity was computed to

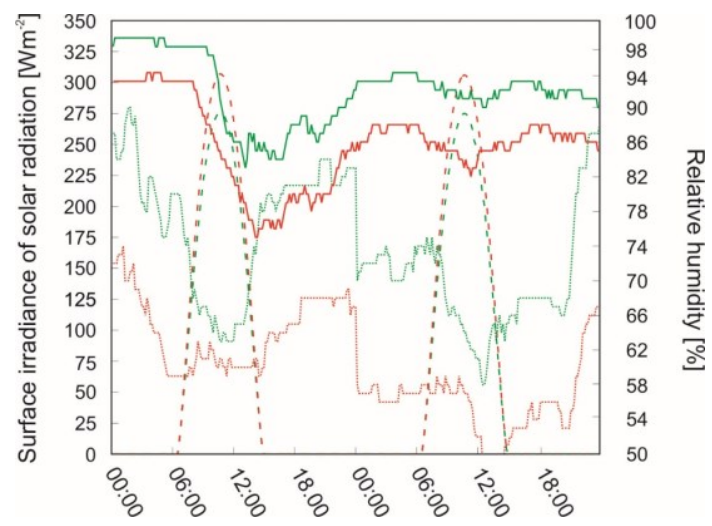

Fig. 6 Temporal variability of observed (solid lines) and modelled (dotted lines) relative humidity in LCZ D (green) and station 5-1 (red). The dashed lines represent the temporal variability of surface irradiance of solar radiation in LCZ D (green) and station 5-1 (red) be higher by $10 \%$. At nights, the differences grows further, particularly from 15 to 10 UTC. Considering the criterion above, fog is predicted only for a small fraction of the simulation time, and exclusively for the rural grids.

The under-representation of moist content can be the reason why the model captures most of the features of $\mathrm{T}_{\mathrm{n}}$ (and so $\Delta \mathrm{T}$ ) with relatively high biases. The well-balanced course of $\mathrm{T}_{\text {noBs }}$ time-series are affected largely by the fog. Due to negligible solar radiation, the surface-induced thermal differences cannot be evolved. In the simulations, controversially, the overestimated insolation is able to store in urban fabrics in the daytime and being reemitted to the overlying atmosphere in the night-time, creating significant daily variations of temperature.

Without proper representation of fog in initial and boundary conditions, the reconstruction of UHI under such synoptic patterns is quite challenging. A possible solution can be is the application of multiple models for initial conditions to find the most suitable option for the corresponding modelling purpose. For our case (and in many others), the assimilation of local measurement could give the "best guess" to derive the initial meteorological field.

\section{2. "Precipitation case"}

\subsubsection{Evaluation of near-surface temperature}

During the days with remarkable precipitation, $\mathrm{T}_{\mathrm{nOBS}}$ fluctuates between $10^{\circ} \mathrm{C}$ and $18^{\circ} \mathrm{C}$ (Fig. 7). At the early stage of the first day, when the cyclone does not modify the progress of urban effect, a regular daily pattern of $\mathrm{T}_{\mathrm{nOBS}}$ develops, with minima (maxima) around 06 UTC (14 UTC). On the second day, however, a gradual cooling occurred due to lack of insolation, moderate rainfall, and cold advection. WRF captures well the transition of $\mathrm{T}_{\mathrm{nOBS}}$ between the days with distinct meteorological background. Focusing on the first day, 
the minimum of $\mathrm{T}_{\mathrm{nWRF}}$ is simulated properly in LCZs 2 and 5 but with different signals elsewhere: as against to the cold biases in LCZ D, warm biases evolves in LCZs 6 and 9. The daytime values are consistently overestimated by $1{ }^{\circ} \mathrm{C}$ to $2^{\circ} \mathrm{C}$ in each LCZ. In many aspects, $\mathrm{T}_{\mathrm{nWRF}}$ indicates a better agreement with the observations on the second day, with absolute biases under $1{ }^{\circ} \mathrm{C}$. From 18 UTC, a slight warming appears in all LCZs, which is not underpinned by the observations and can be linked to the misinterpretation of rainfall length.
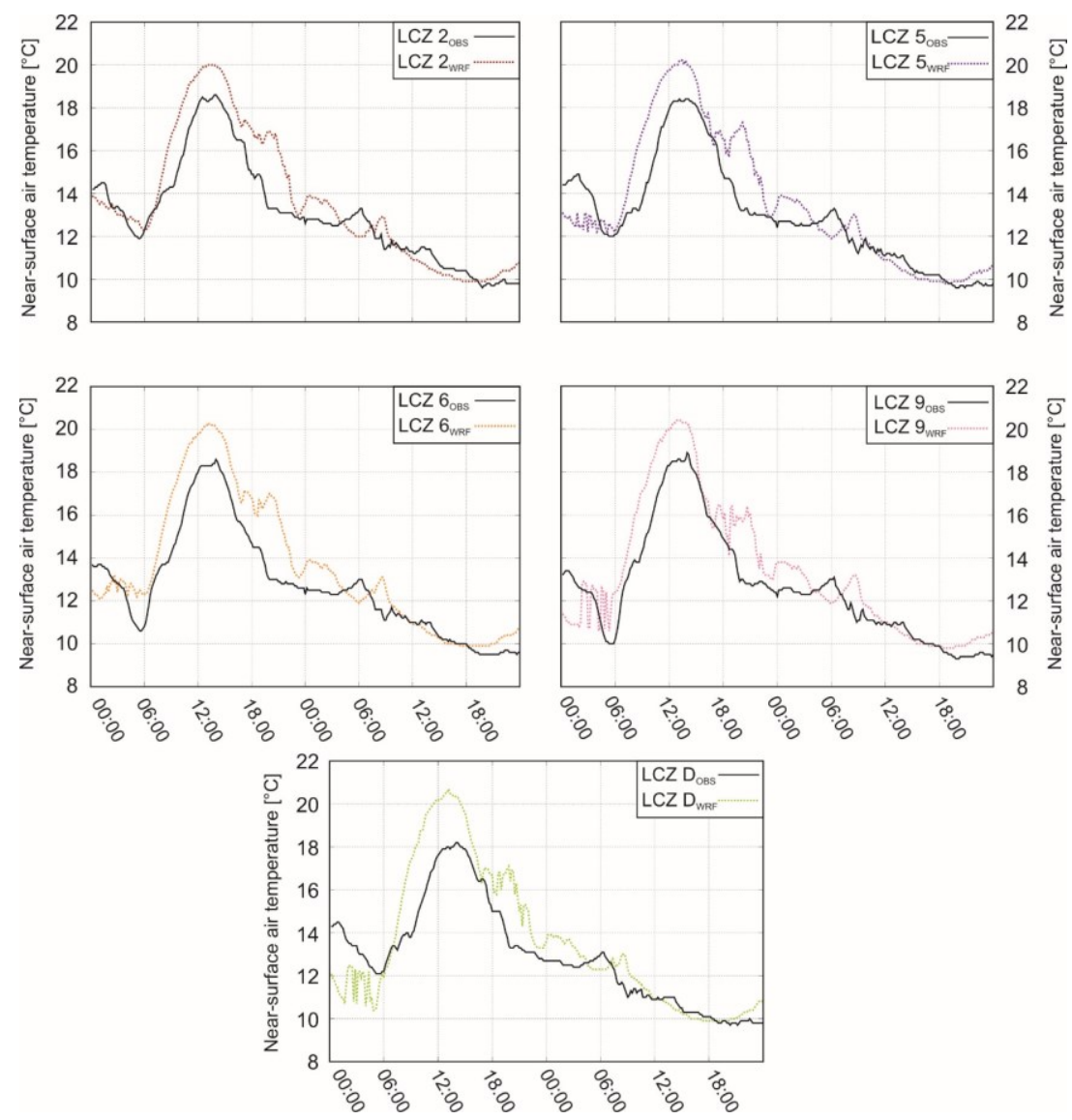

Fig. 7 Temporal variation of observed and modelled near-surface air temperature in each LCZ

Fig. 8 confirms that the weather conditions were not favoured for the development of urban heat island; $\Delta \mathrm{T}_{\mathrm{OBS}}$ scatters between $-1{ }^{\circ} \mathrm{C}$ and $1{ }^{\circ} \mathrm{C}$ and becomes invariant as the precipitation event begins. The largest uncertainties of $\Delta \mathrm{T}_{\mathrm{WRF}}$ arises at the first hours of the simulation, when the rain has not started to fall. After sunset of 22 October, there are overestimations of $2-3^{\circ} \mathrm{C}$, particularly in LCZs 6 and 9 . The negative biases, predicted in the middle of the day, are considerably in those LCZs where $\Delta \mathrm{T}$ is observed to be higher during this period. As it is discussed earlier, this general under-prediction stems from lower modelled cloud coverage (higher modelled incoming solar radiation) and so higher $\mathrm{T}_{\mathrm{nWRF}}$.

In Fig. 9 the thermal differences of $\Delta \mathrm{T}_{\mathrm{WRF}}$ over urban and non-urban parts of the study area are illustrated. The shifting in the synoptic situation and its influence on the shape of 
urban heat island is captured well by WRF. In the dawn of the first day (04 UTC), a wellpronounced UHI is simulated, with intensities around $2^{\circ} \mathrm{C}$. As it is expected, no considerable difference in $\Delta \mathrm{T}_{\mathrm{WRF}}$ is depicted during the day. After sunset, the urban effect amplifies again, but with less magnitude due to the arrival of cyclonic system. As the time goes by, $\Delta \mathrm{T}_{\mathrm{WRF}}$ increases to $0^{\circ} \mathrm{C}$ and UHI is entirely blurred. In other words, the inhomogeneity of surface geometry has slightly visible and sensible impact on the distribution of local meteorological variables. Without insolation, the singe income term of energy budget is the anthropogenic heat. In autumn, the most common form of heat release from human activity is the heating of buildings. Under such weather conditions, the urban boundary layer is well-mixed, so this additional energy surplus cannot be cumulated over areas with higher built-up and does not increase of urban-rural thermal contrast.
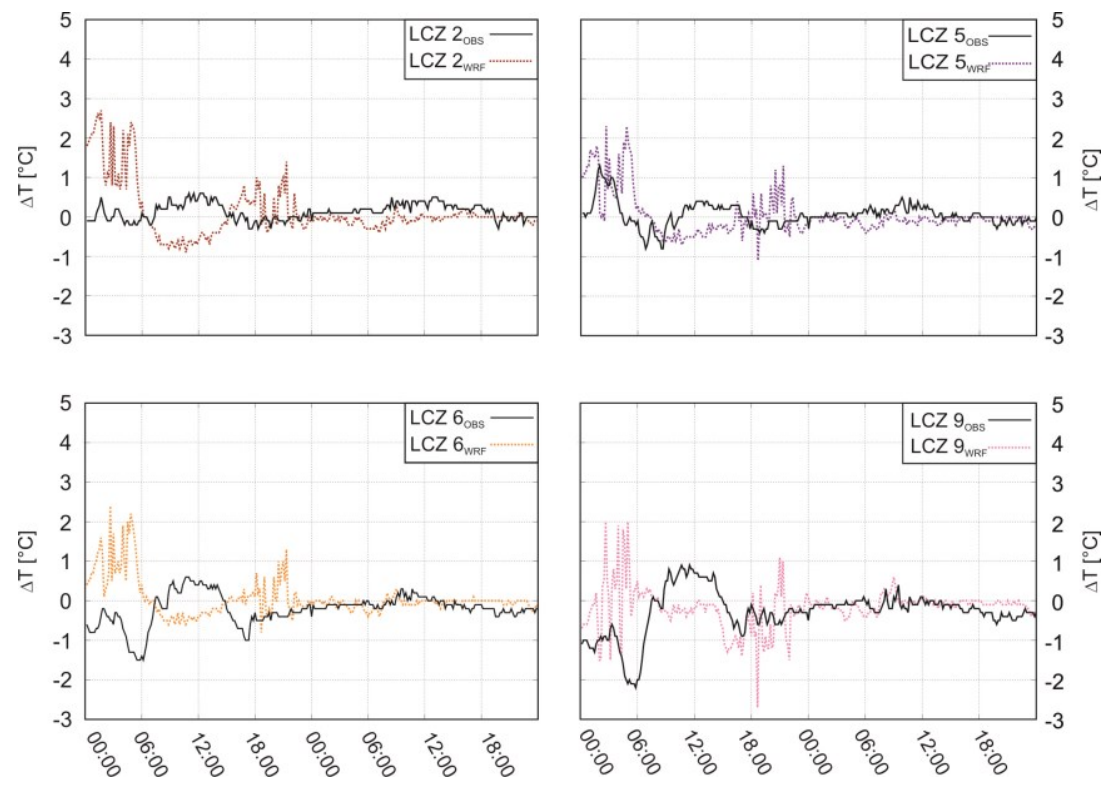

Fig. 8 Temporal variation of observed and modelled urban heat island intensity $(\Delta \mathrm{T})$ in each LCZ

Fig. 10 shows the evolution of precipitation field over Hungary during the second day of the simulation period. The largest amount of precipitation is modelled around 00 UTC, with hourly sums around $5 \mathrm{~mm}$. As the centre of the cyclone (mean see level pressure around $1004 \mathrm{hPa}$ ) approaches Szeged (around 12-13 UTC), the rainfall intensity decreases to 2-3 $\mathrm{mm}$, however, still remarkable moist convergence is predicted at the western side of the centre. The dissipation of the system starts in the late afternoon, the hourly sums stays below $1 \mathrm{~mm}$ at 20 UTC. Later, the rainfall ceases according to the simulations.

The predicted hourly precipitation sums is evaluated through the measured values at station D-1 (Fig. 11). Under the evaluation process, three types of biases are introduced. The "standard" bias means the modelled bias (observed value subtracted from the modelled one) when the precipitation at a given hour is included both in the observations and outputs.

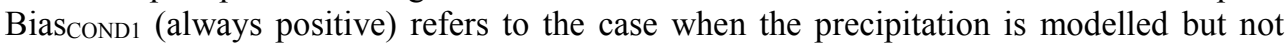
measured. Bias COND2 (always negative) refers to the case when the precipitation is measured but not modelled. Following this assumption, it is revealed that the rainfall in WRF is 
simulated first at 18 UTC (on 22 October), but it is not supported by the observations. In real, the precipitation starts to fall in the next hour, which is not caught by WRF. In the hours afterwards, the hourly rainfall sums is mostly underestimated with about $1-2 \mathrm{~mm}$. At 22 UTC a significant positive bias of $7 \mathrm{~mm}$ occurs. From 05 to 17 UTC, hourly sums over $1.5 \mathrm{~mm}$ is predicted, without the confirmation of the observations. At the end of the simulation period slight underestimations are illustrated. This can be the reason why $T_{n}$ is simulated to be higher in contrast with $\mathrm{T}_{\mathrm{nOBS}}$.

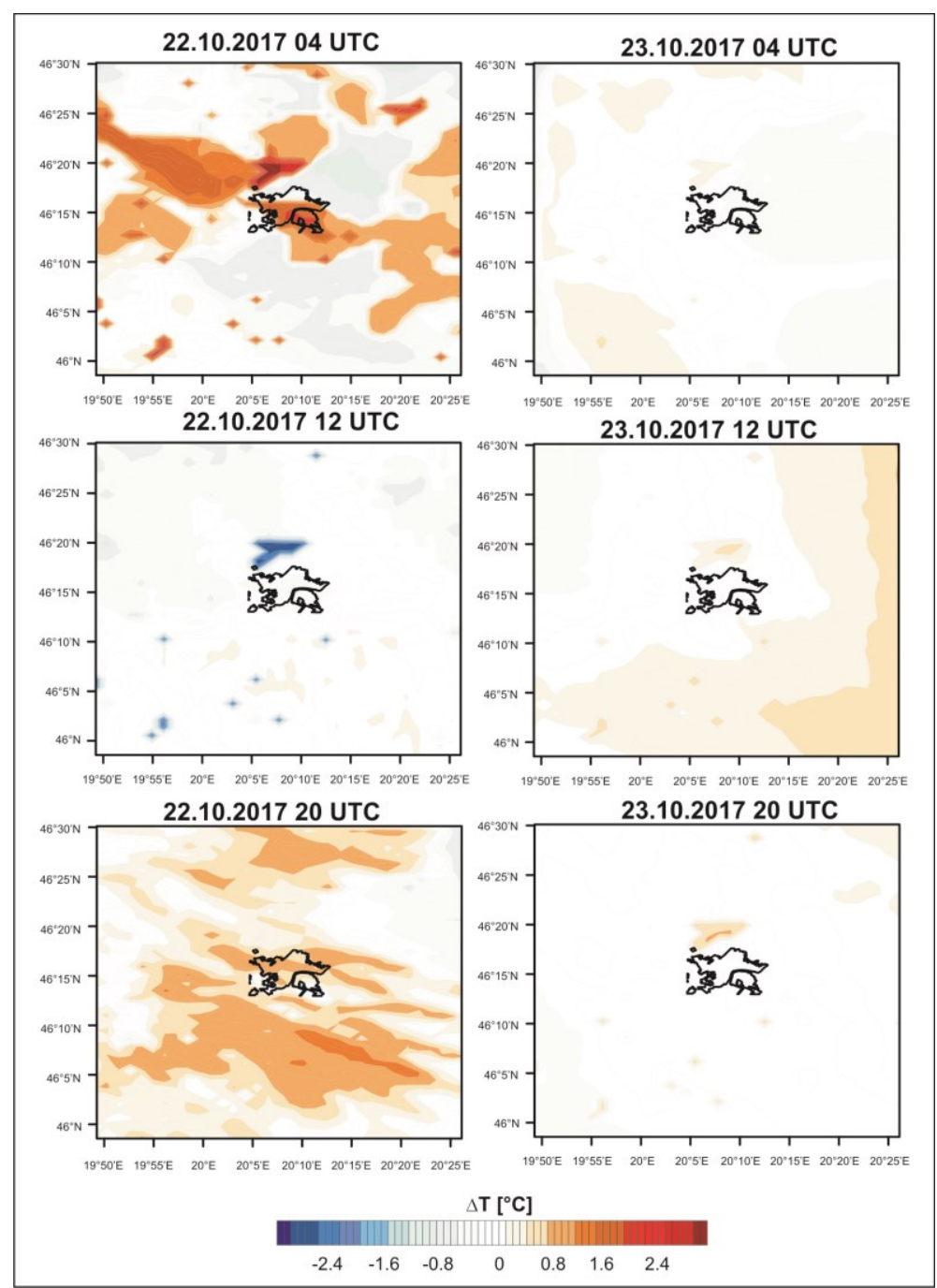

Fig. 9 Spatial distribution of modelled urban heat island intensity $(\Delta \mathrm{T})$ over the Szeged and the surroundings on six distinct dates 


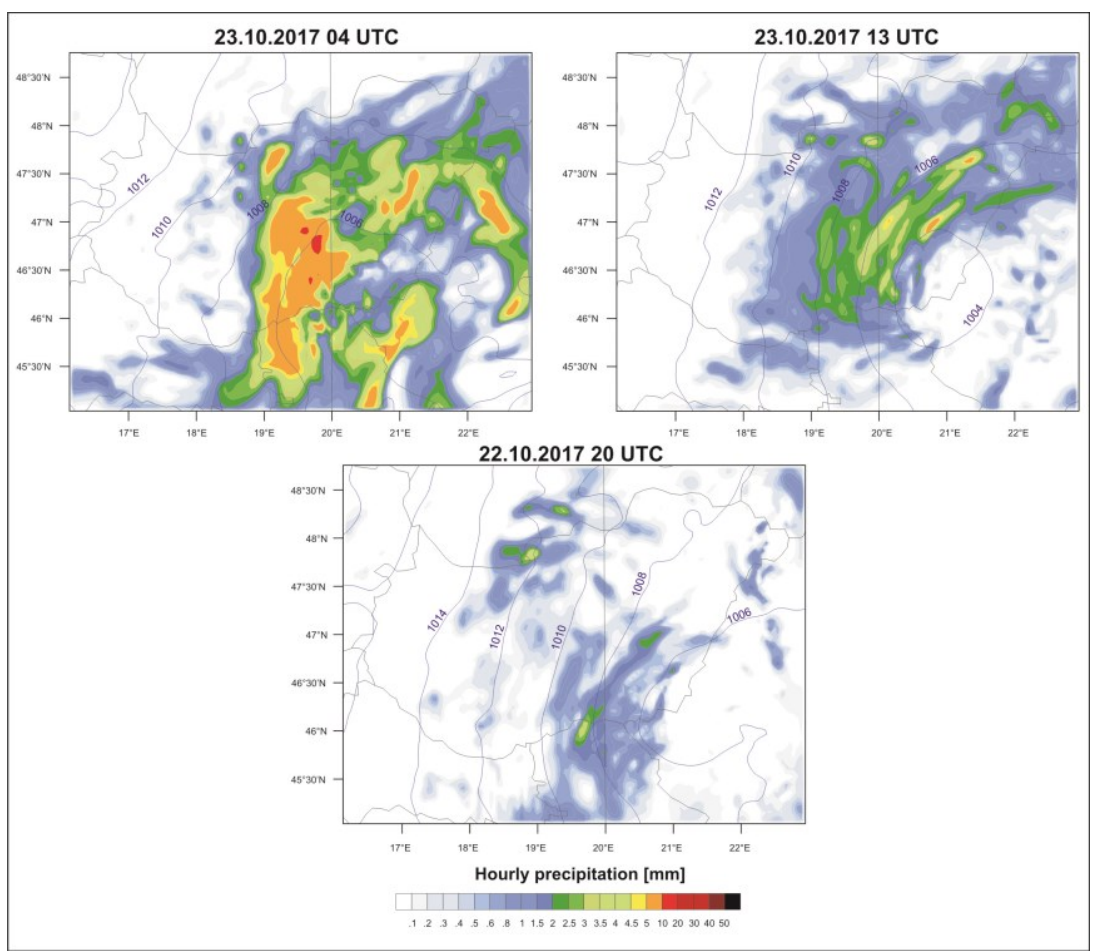

Fig. 10 Spatial distribution of modelled hourly sums of precipitation and mean see level pressure over Hungary on three distinct dates

\section{CONCLUSIONS}

In this study, the urban heat island effect was simulated with WRF under non-ideal (i.e. fog and precipitation) meteorological conditions. It was analysed that whether the model is able to predict the influence of strong synoptic forcing on the evolution of thermal and moisture-related variables in the complex urban canopy layer. The modelled outputs of near-surface air temperature, urban heat island intensity, relative humidity, and precipitation sums was evaluated against the observations of our urban climate monitoring system.

During the first simulation period, thick fog layer covered the Carpathian Basin. Due to lack of insolation, the observed near-surface air temperatures had low temporal variation and ranged $-3^{\circ} \mathrm{C}$ and $0^{\circ} \mathrm{C}$. On the other hand, the predicted diurnal variabilities exceeded $5^{\circ} \mathrm{C}$. The overestimations in the daytime, however, slightly decreased on the second day. At nights, the near-surface air temperature was simulated

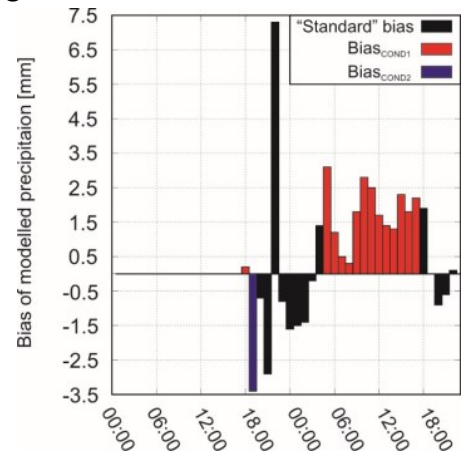

Fig. 11 Comparison of observed and modelled hourly precipitation sums at station D-1 
better on the first day, with absolute biases lower than $1.5^{\circ} \mathrm{C}$. According to the observations, only a weak urban effect was created under this synoptic pattern. As a result of the higher predicted temperatures in each urban LCZ related to the rural LCZ D, the urban heat island intensity was found to be $1.5-2^{\circ} \mathrm{C}$ higher in the simulations. Spatially, UHI has developed with the highest simulated magnitudes over areas classified as LCZs 2 and 5. LCZs with lower artificial surface coverage (e.g. LCZs 9 and D) were characterized by less pronounced urban effect. The relatively errors of WRF can be contributed to the under-prediction of air moisture content. While the observed relative humidity was around $80 \%$, the observed values remained below this threshold, in fact, during the entire period. It means that the fog was almost totally excluded from the simulations, which has caused the remarkable variations of temperature and heat island intensity.

The second simulation period coincided with the pass of a Mediterranean low over Szeged, characterized by significant rainfall. It can be concluded that WRF has performed much better in terms of all variables. The largest uncertainties of near-surface temperature evolved on the first day when the precipitation event has not started yet. Then, the nocturnal values were caught adequately, although some underestimations of $1.5-2^{\circ} \mathrm{C}$ occurred during the daytime. On the next day, when the cyclonal system had more effect on the local meteorology, WRF predicted reasonably better the overall pattern of near-surface temperature in all LCZs. The drastic shift in urban effect between the two days of this period was also predicted with small biases. Due to intense rainfall, the simulated heat island intensity decreased $2-2.5^{\circ} \mathrm{C}$ in the downtown and stagnated around $0^{\circ} \mathrm{C}$ during the entire day. The evaluation of modelled hourly sums of precipitation suggested that pass of the rain field was captured appropriately in most of its aspects. Overall, more precipitation was simulated as it may be expected from the observations. The largest positive biases were created on the second day from 04 to 17 UTC. Meanwhile, the rainfall was modelled but not recorded by the measurements. This mistake has not caused significant biases in temperature, since the attenuation of solar radiation could be equal both in WRF and the observations.

As a conclusion, during the precipitation case, the model with our settings modelled the urban effect with relatively good agreement with the observations. The simulation of the synoptic pattern with thick fog layer, however, were followed by significant uncertainties. The evaluation of relative humidity in an urban and rural station confirmed that the existence of fog or mist was not reproduced by the model at all. The forecast of fog is one of the most difficult modelling challenge. Since this phenomenon acts typically on local scale, the horizontal resolution of grid and the selection of parameterization schemes is particularly crucial. If the global model that provides the initial and boundary conditions for WRF is not able to represent some of the important feature of the atmosphere over the region of interest, the simulation of WRF can also be inaccurate. To overcome this problem, it is advisable to use more model for reproducing the initial meteorological field and find which of those the best choice under a specific synoptic situation is. Moreover, the assimilation of local measurements can also be a reliable solution. For this reason, we aim to execute a 3dimensional variational data assimilation of near-surface temperature and relative humidity, measured by our urban climate monitoring system. Hopefully, it can contribute to a better representation of the initial meteorological field, particularly under strong external synoptic forcing. 


\section{REFERENCES}

Bergot T, Carrer D, Noilhan J, Bougeault P (2005) Improved site-specific numerical prediction of fog and low clouds: A feasibility study. Weather Forecast 20:627-646

Bokwa A, Wypych A, Hajto MJ (2018) Role of fog in urban heat island modification in Kraków, Poland. Aerosol Air Qual Res 18:178-187

Bougeault P, Lacarrere P (1989) Parameterization of orography-Induced turbulence in a mesobeta-scale model. Mon Weather Rev 117:1872-1890

Fallmann J, Forkel R, Emeis S (2016) Secondary effects of urban heat island mitigation measures on air quality. Atmos Environ 125:199-211

Gao X, Gao S, Yang Y (2018) A comparison between 3DVAR and EnKF for data assimilation effects on the Yellow Sea fog forecast. Atmosphere-Basel 9:346

Hong SY, Dudhia J, Chen SH (2004) A revised approach to ice microphysical processes for the bulk parameterization of clouds and precipitation. Mon Weather Rev 132:103-120

Iacono MJ, Delemere JS, Mlawer EJ, Shephard MW, Clough SA, Collins WD (2008) Radiative forcing by longlived green-house gases: Calculations with the AER radiative transfer models. J Geophys Res 113:D13103

Jimenez PA, Dudhia J, Gonzalez-Rouco JF, Navarro J, Montavez JP, Garcia-Bustamante, E (2012) A revised scheme for the WRF surface layer formulation. Mon Weather Rev 140:898-918

Kain JS (2004) The Kain-Fritsch convective parameterization: An update. J Appl Meteor 43:170-181

Kis A, Pongrácz R, Bartholy J (2017) Multi-model analysis of regional dry and wet conditions for the Carpathian Region. Int J Climatol 37:4543-4560

Kottek M, Grieser J, Beck C, Rudolf B, Rubel F (2006) World map of the Köppen-Geiger climate classification update. Meteorol Z 15:259-263

Kusaka H, Kondo H, Kikegawa Y, Kimura F (2001) A simple single-layer urban canopy model for atmospheric models: Comparison with multi-layer and slab models. Bound-Lay Meteorol 101:329-358

Kusaka H, Kimura F (2004) Coupling a single-layer urban canopy model with a simple atmospheric model: Impact on urban heat island simulation for an idealized case. J Meteorol Soc Jpn 82:67-80

Lelovics E, Unger J, Gál T, Gál CV (2014) Design of an urban monitoring network based on Local Climate Zone mapping and temperature pattern modelling. Clim Res 60:51-62

Martilli, A, Clappier A, Rotach MW (2002) An urban surface exchange parameterization for mesoscale models. Bound-Lay Meteorol 104:261-304

Morris CJG, Simmonds I, Plummer N (2001) Quantification of the influences of wind and cloud on the nocturnal Urban Heat Island of a large city. J Appl Meteorol 40:169-182

Oke TR (1987) Boundary Layer Climates, 2nd ed. Routledge, London

Péliné Németh Cs, Bartholy J, Pongrácz R, Radics K (2015) Analysis of climate change influences on the wind characteristics in Hungary. Időjárás 120:53-71

Rémy S, Bergot T (2010) Ensemble Kalman filter data assimilation in a 1D numerical model used for fog forecasting. Mon Weather Rev 138:1792-1810

Salamanca F, Martilli A (2010) A new building energy model coupled with an urban canopy parameterization for urban climate simulations-part II. Validation with one dimension offline simulations. Theor Appl Climatol 99:345-356

Skamarock WC, Klemp JB, Dudhia J, Gill DO, Barker DM, Duda MG, Huang XY, Wang W, Powers JG (2008) A description of the advanced research WRF version 3. NCAR Tech. Note NCAR/TN-475+STR

Steeneveld GJ, Ronda RJ, Holtslag AAM (2015) The challenge of forecasting onset and development of radiation fog using mesoscale atmospheric models. Bound-Lay Meteorol 154:265-289

Stewart ID, Oke TR (2012) Local Climate Zones for urban temperature studies. B Am Meteorol Soc 93:1879-1900

Tan J, Zheng Y, Tang X, Guo C, Li L, Song G, Zhen X, Yuan D, Kalkstein AJ, Li F, Chen H (2010) The urban heat island and its impact on heat waves and human health in Shanghai. Int J Biometeorol 54:75-84

Tewari M, Chen F, Wang W, Dudhia J, LeMone MA, Mitchell K, Ek M, Gayno G, Wegiel J, Cuenca RH (2004) Implementation and verification of the unified NOAH land surface model in the WRF model. 20th Conference on Weather Analysis and Forecasting/16th Conference on Numerical Weather Prediction

Tudor M (2010) Impact of horizontal diffusion, radiation and cloudiness parameterization schemes on fog forecasting on valleys. Meteorol Atmos Phys 108:57-70

Vardoulakis E, Karamanis D, Fotiadi A, Mihalakakou G (2013) The urban heat island effect in a small Mediterranean city of high temperatures and cooling energy demands. Sol Energy 94:128-144

Wang SK, Kuo S (2001) Handbook of Air Conditioning and Refrigeration. McGraw-Hill, New York 